ISSN: 2277-3754

ISO 9001:2008 Certified

International Journal of Engineering and Innovative Technology (IJEIT)

Volume 10, Issue 3, September 2020

\title{
Leaf disorder recognition with region - based segmentation and statistical measurements
}

\begin{abstract}
Alexander V Gark
in which agricultural
Abstract - India is a country in which agricultural

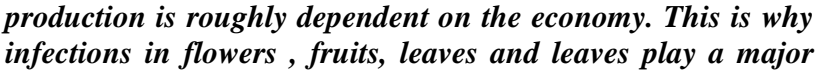
role in agriculture as they are relatively common with infection on ground. Where reasonable action may be taken to ensure that plants have considerable properties and because of which the percentage, quantity or efficiency of output are affected. For the proposed work we try to explain the type of disease detection with the help of Artificial Neural Network approach in this method we have a very huge amount of dataset which either save in the system or save in the server if this work can be implanted over worldwide. For implantation of the work MATLAB software is used with the help of ANN the infected sample is selected or online we can take any sample by on site clicking the photograph of any leaf, flower, crop, vegetable and call this sample by MATLAB GUI and then enhance the contrast of sample image then we segment the image by clustering approach we can separate the image in different cluster and each cluster can be properly examined by the simulation tools. There are various parameters that can be calculated by the software like Mean, Standard image. This proposed algorithm which help us to Analyze the sample of any of the agricultural product either it can use on site or by the help of any of the communication method to collect the sample real time implementation of the proposed algorithm is also possible.
\end{abstract}

\section{INTRODUCTION}

The agriculture sector is the main contributor in Indian economy and doing well in white, green and blue revolution. According to APEDA by 2014 export of Indian agriculture will reach to $5 \%$ of total production of the world and rank 10th in the ranking [1].

Digital Image Processing: - Advanced picture handling is essential field of outlining and development. In current period each field relies upon the employments of modernized picture dealing with, in cutting edge picture getting ready, automated depiction of pictures for the most part require a generous number of bits. In various applications, it is basic to examine approach for suggesting a photo, or the information contained in the photo, with less bits. By wiping out dull or unnecessary information, picture weight is the development that tends to this point. Picture getting ready systems have been associated with a couple of scopes of picture and video taking care of, for instance, correspondence, video conferencing et cetera. In the automated picture and video weight it is required to diminish bit rate need and improves speed of transmission.

Image Compression - Picture pressure is essential term for successful transmission and picture stockpiling.

Manuscript received: 29 August 2020

Manuscript received in revised form: 25 September 2020

Manuscript accepted: 10 October 2020

Manuscript Available online: 15 October 2020
Necessity of picture pressure is in correspondence framework for the information and picture change, it is need of telecom industry, in the field of sight and sound information in the broadcast communications system and ring the mixed media information through Internet. Some other necessity of picture pressure is as in the field of advanced cameras, prerequisites for information stockpiling, control, and exchanges of computerized pictures, has grown violently. These picture records can be huge and can involve expansive memory.

Feature Extraction - By feature extraction we can diminish the picture into few numbers or gatherings of numbers that depict the material components of the picture. These components fundamental be deliberately chosen such that they create great portrayal of the picture and outline the basic data. Certain cases of elements are mean, standard deviation, angle and edges of picture. More often than not, a gathering of components is utilized to deliver a model for the pictures. By Cross validation on the pictures we can see which highlights speak to the picture well.

IMAGE SEGMENTATION - In general, image segmentation is the first step in an attempt to automatically analyze or interpret an image. The method of grouping pixels with similar attributes may likewise be considered. Divided images into various areas that should closely correlate with artefacts as characteristics of interest for the photo. Segmentation is a key component of the computer vision system, as errors are propagated through the method to higher analytical processes and the difficulty of subsequent work is increased. Ideally, the following characteristics should apply to the segments within the image

Segmentation Techniques: - In segmentation phase, the image (such as multi-resolution, multispectral) is divided into its constituent parts
D Thresholding Based Methods
$>$ Edge Based Methods
$>$ Region Based Segmentation Method
$>$ Clustering Based Segmentation Method
$>$ Watershed Based Methods
$>$ PDE Based Method
$>$ ANN Based Method

\section{PROBLEM STATEMENT}

In past work we have found some inconveniences and shortcomings according to the various methods since its drawback in Thresholding method is heavily dependent upon peak values. The edge-based method is not suited for so many edges. The region-based method is costly in memory. Image segmentation is the commonly researched area of image processing, image interpretation 
ISSN: 2277-3754

ISO 9001:2008 Certified

\section{International Journal of Engineering and Innovative Technology (IJEIT)}

\section{Volume 10, Issue 3, September 2020}

and an important early vision issue module. Image segmentation is the method of dividing an image into disjointed or distinct areas, which have similar characteristics such as intensity, color, texture etc. With regard to these features, no two such regions are similar [1][2]. Digital image analysis usually includes "low level" and "high level" processing of digital image processing. In low-level analysis image representation is transformed into a symbolic group of primitive images: edges and regions, from a numerical array of pixel intensities. These primitives are given label(s) of the object in high-level analysis, providing a semantic definition of the image. For monochrome images, the segmentation algorithms are typically based on one of two simple gray-level properties: discontinuity and similarity. The preprocessing phase results in the segmentation phase, which is performed until it is sent to post processing and the output image is segmented. When the front is separated from the background picture, the actual segmentation is stopped. The segmentation of a digital image into many areas (pixel sets) is a part of an image analysis based on certain parameters. Usually, the purpose of segmentation is to locate certain subjects that may be seen in the picture. Therefore segmentation could be seen as an issue with computer vision. The picture can be purchased with different kinds of image acquisition devices transferred to the preprocessing unit from some issue domains. Our main function is to enhance the image in order to increase the probability of success for the other method. We try to address the complexities and shortcomings of the previous approach in our study.

\section{PLANT DISEASES}

1. Alternaria - The Alternaria form is an organism which is very sensitive. In most quiet areas, Alternaria spores can be found in spring to pre-winter and can achieve thousands of spores for every cubic metre of air. In the dry, freezing conditions that are ideal for the spores to finish airborne, Alternaria spores will at its highest fixation. Right now, Alternaria has about 40-50 species. The soil, soil, sustenance and indoor air are normally disengaged by plants. Alternaria alternative, one of the animal groups, has been confined to many natural materials, including materials, fabric, carton, paper, electric ties, polyurethane, fuel, sewer and effluent, in a soggy setting. In several foods grown far and wide from the ground, Alternaria Alternata makes dark spot

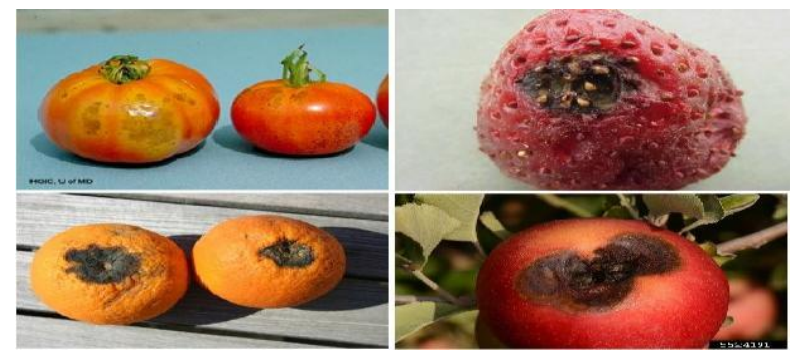

Fig.1.Sample of Alternaria
2. Anthracnose- Multiple plants, including plants, fruit and trees. It is based on dullness, leaves, stalks, flowers, fruits and dipped lesions. Unindustrialized releases and leaves are also made. It spreads over droughty periods quite rapidly. Anthracnose is a common word for a number of diseases that similarly affect plants. Anthracnose is noted in particular for its damage to the trees. Fungus causes anthracnose, and it attacks cucurbits between vegetables. Anthracnose can live and spread very easily on contaminated plant debris. It grows like rust, and sometimes spreads by watering under hot and moist conditions. Anthracnosis is a fungal illness that in the spring tends to attack plants, particularly on leaves and twigs, when the weather is cool and moist. In dead twigs and dropping leaves, the fungi overwinter.
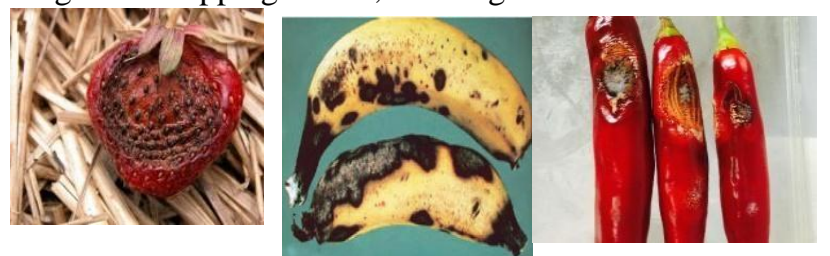

Fig.2.Sample of Anthracnose

3. Bacterial Blight - Bacterial mildew is a problem for snapshots and lima beans most often in vegetable garden. Symptoms of infection are large, water-soaked pale-green spots on leaves that later become Brown. (Note that other plants often suffer from bacterial disease which may be called bacterial blight.) These spots can also be found on pods and in wet conditions can cause yellowish ooze. Halo bacterial blight infected leaves grow several small dead spots around them with yellow halos, and spots on pods create cream-colored ooze. Bacterial blight is a common soybean condition most common in cold, wet environments.
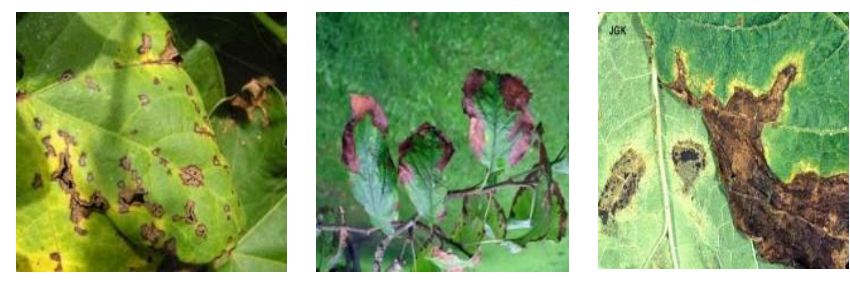

Fig.3.Sample of Bacterial Blight

\section{PROPOSED ALGORITHM}

Step 1 - Provide the input as the image of the leaf to be detected.

Step 2 contrast is enhanced by gray scale conversion.

Step 3 -Clustering.

Step 4 Selection of the cluster to be tested.

Step 5 -Image classification for the disease.

Step 6 -Calculation of affected region (in \%).

Step 7 -Mean, Standard Deviation, Entropy, RMS, Variance, Smoothness, Kurtosis, Skewness, IDM, Contrast, Correlation, Energy \& Homogeneity are calculated.

Step 8 -Accuracy of the Whole process is calculated (in $\%)$.

Step 9 - End the Process. 


\section{|VEIT}

ISSN: 2277-3754

ISO 9001:2008 Certified

International Journal of Engineering and Innovative Technology (IJEIT)

Volume 10, Issue 3, September 2020

\section{SIMULATION RESULT}

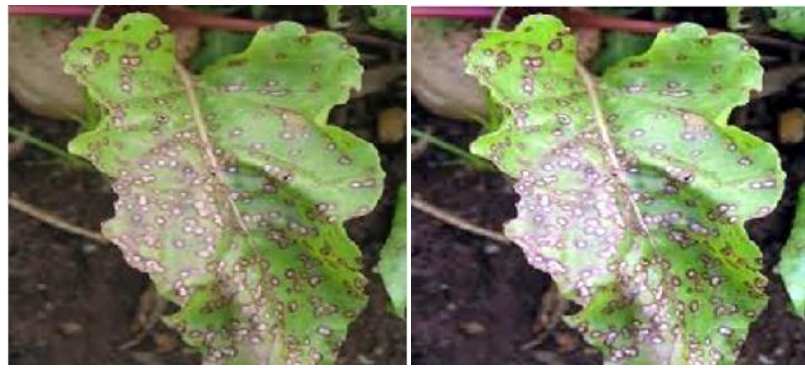

Fig.4 (a) Original Leaf Sample-1image (b) Enhance Leaf sample-1
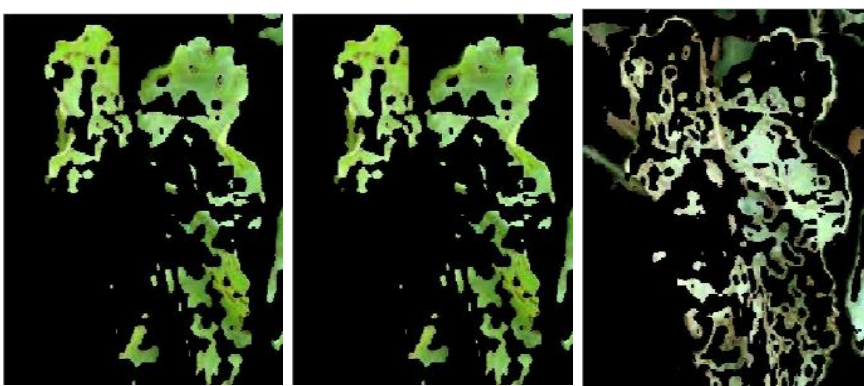

Fig.5. (a) Leaf Sample-1 cluster 1 (b) Leaf Sample-1 cluster 2 (c) Leaf Sample-1 cluster 3

Table 1.Various Parameter Representation of Leaf
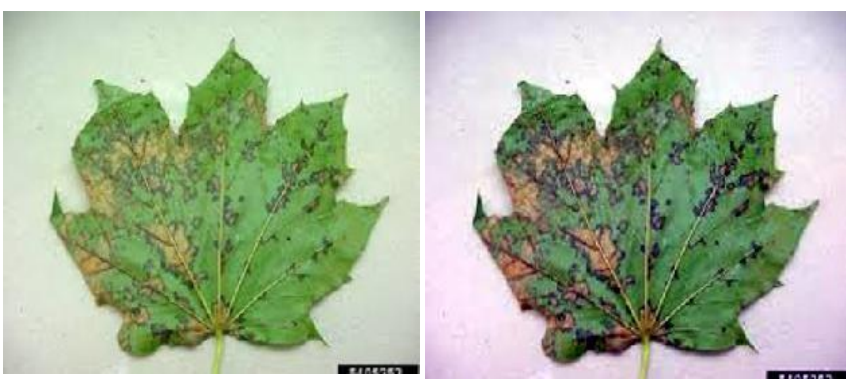

Fig.6. (a) Original Leaf Sample-2image (b) Enhance Leaf sample-2
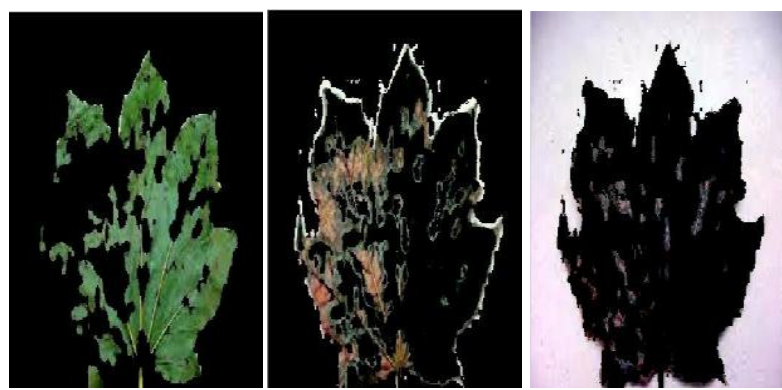

Fig.7. (a) Leaf Sample-2 cluster 1 (b) Leaf Sample-2 cluster 2 (c) Leaf Sample-2 cluster 3

\begin{tabular}{|c|c|c|c|c|c|c|}
\hline \multirow{2}{*}{ Parameter } & \multicolumn{3}{|c|}{ Leaf 1} & \multicolumn{3}{|c|}{ Leaf 2} \\
\hline & Cluster 1 & Cluster 2 & Cluster 3 & Cluster 1 & Cluster 2 & Cluster 3 \\
\hline Mean & 27.1284 & 51.6916 & 38.0943 & 23.0405 & 19.741 & 125.297 \\
\hline Standard Deviation & 59.8425 & 70.9386 & 70.5127 & 43.933 & 49.3344 & 113.644 \\
\hline RMS & 6.25774 & 11.1231 & 7.88447 & 6.50398 & 5.62567 & 11.7224 \\
\hline Affected Region & None & 23.0239 & 15.4723 & None & 11.9856 & 54.8143 \\
\hline Skewness & 2.04333 & 1.37981 & 1.57705 & 1.69797 & 2.69714 & 0.130672 \\
\hline Entropy & 2.17868 & 4.98209 & 2.84788 & 2.50491 & 1.95386 & 4.55941 \\
\hline Kutosis & 5.80185 & 3.71987 & 3.95334 & 4.6354 & 9.92354 & 1.08482 \\
\hline Contrast & 0.689737 & 0.831679 & 1.41762 & 0.41296 & 1.00107 & 0.63223 \\
\hline Smoothness & 1 & 1 & 1 & 1 & 1 & 1 \\
\hline Correlation & 0.902025 & 0.899591 & 0.842934 & 0.877485 & 0.748981 & 0.970744 \\
\hline Energy & 0.629246 & 0.300285 & 0.504534 & 0.557554 & 0.644755 & 0.316481 \\
\hline Homogeneity & 0.956463 & 0.915275 & 0.910164 & 0.937106 & 0.919102 & 0.959639 \\
\hline IDM & 255 & 255 & 255 & 255 & 255 & 255 \\
\hline Variance & 3107.81 & 4409.05 & 4535.94 & 1474.3 & 2162.61 & 8577.5 \\
\hline Accuracy in \% & 98.3871 & 96.7742 & 96.7742 & 98.3871 & 96.7742 & 96.7742 \\
\hline Classification Result & $\begin{array}{l}\text { Healthy } \\
\text { Leaf }\end{array}$ & $\begin{array}{c}\text { Cercospora } \\
\text { Leaf Spot }\end{array}$ & $\begin{array}{c}\text { Cercospora } \\
\text { Leaf Spot }\end{array}$ & $\begin{array}{c}\text { Healthy } \\
\text { Leaf }\end{array}$ & Anthracnose & $\begin{array}{l}\text { Alternaria } \\
\text { Alternata }\end{array}$ \\
\hline
\end{tabular}


ISSN: 2277-3754

ISO 9001:2008 Certified

International Journal of Engineering and Innovative Technology (IJEIT)

Volume 10, Issue 3, September 2020

\section{CONCLUSION AND FUTURE SCOPE}

This method can be used to build a framework for farmers who have soybeans for the diagnosis, diagnosis and distance treatment of early foliar infections. Through this paper, we have been looking at the issues relating to soybean production in developing countries, including India, and the causes of low-yield losses. A full automatic system has been proposed and various new parameters and indices such as DSI, IPR, and DLP have been developed that can be used in the prediction of disease. Seventies foliar soy diseases are taken, namely; rust, bacterial blight, Sudden Death Syndrome, Brown Spot, Downy Mildew and frog eye, mainly due to substantial loss of yields. The technique was applied successfully and real soy leaf data were collected. The impact is persuasive, wide adaptability and in developed countries where such data are an important factor in improving performance. The proposed technique uses handheld cams to capture the ill images which needs no specialized training which advanced equipment. I for ROI estimation, context separation and parameter, the proposed method is totally automatic.

\section{REFERENCES}

[1] Singh, Vijai, and A. K. Misra. "Detection of plant leaf diseases using image segmentation and soft computing techniques." Information Processing in Agriculture Vol 4, no. 1, pp: 41-49, 2017.

[2] Dey, Amar Kumar, Manisha Sharma, and M. R. Meshram. "Image processing based leaf root disease, detection of betel vine (Piper BetleL.)." Procedia Computer Science 85, pp: 748-754, 2016.

[3] Soni, Amar Prasad, Amar Kumar Dey, and Manisha Sharma. "An image processing technique for estimation of betel leaf area", IEEE International Conference on Electrical, Electronics, Signals, Communication and Optimization (EESCO), pp. 1-5, 2015.

[4] Pawan P. Warne, Dr. S.R. Ganorkar, "Detection of Diseases on Cotton Leaves Using K-Mean Clustering Method", International Research Journal of Engineering and Technology (IRJET) Volume: 02 Issue: 04, pp: 425431, July-2015.

[5] Daisy Shergill, Akashdeep Rana, Harsimran Singh "Extraction of rice disease using image processing", International Journal Of Engineering Sciences \& Research technology, pp:135- 143, June, 2015.

[6] Malvika Ranjan, Manasi Rajiv Weginwar, Neha Joshi, A.B. Ingole, "Detection and classification of leaf disease using artificial neural network", International Journal of Technical Research and Applications Volume 3, Issue 3, PP. 331-333, May-June 2015.

[7] Renuka Rajendra Kajale, "Detection \& recognition of plant leaf diseases using image processing and android OS", International Journal of Engineering Research and General Science Volume 3, Issue 2, Part 2, PP:6-9, March-April, 2015.

[8] Prakash M. Mainkar, Shreekant Ghorpade, Mayur Adawadkar," Plant Leaf Disease Detection and
Classification Using Image Processing Techniques", International Journal of Innovative and Emerging Research in Engineering Volume 2, Issue 4, pp: 139-144, 2015. 